\section{High-performance liquid chromatography as a diagnostic tool in prolonged neuro- muscular blockade}

Devanand Mangar MD, Peter B. Kane MD
We report the use of high-performance liquid chromatography (HPLC) to identify the cause of prolonged neuromuscular blockade in a child who had received $2 \mathrm{mg} \cdot \mathrm{kg}^{-1}$ of succinylcholine. Upon analysis by HPLC the syringe was found to contain succinylcholine $\left(10 \mathrm{mg} \cdot \mathrm{ml}^{-1}\right)$ and also atracurium $\left(5 \mathrm{mg} \cdot \mathrm{ml}^{-1}\right)$, so that a diagnosis was established. In situations where medication errors are suspected, we recommend saving syringe contents for analysis for confirmation of the agent.

On rapporte l' utilisation de la chromotographie liquide à haute performance (HPLC) afin d'identifier la cause d'un bloc neuromusculaire prolongé chez un enfant ayant reçu $2 \mathrm{mg} \cdot \mathrm{kg}^{-1}$ de succinylcholine. Après l'analyse par HPLC, on a constaté que la seringue contenait de la succinylcholine $\left(10 \mathrm{mg} \cdot \mathrm{ml}^{-1}\right.$ ) et aussi de l'atracurium (5 $\left.\mathrm{mg} \cdot \mathrm{ml}^{-1}\right)$, établissant ainsi le diagnostic. Dans les situations où des erreurs médicamenteuses sont suspectées, on recommande de garder le contenu de la seringue pour analyse et confirmation sur la nature de l'agent utilisé.

\section{Key words \\ MEASUREMENT TECHNIQUES: HPLC; \\ NEUROMUSCULAR RELAXANTS: atracurium, succinylcholine.}

From the SUNY Health Science Center, The Department of Anaesthesiology, 750 East Adams Street, Syracuse, NY 13210.

Address correspondence 10: Dr. Devanand Mangar, University of South Florida, 12901 Bruce B. Downs Blvd., Box 59, Tampa, Florida 33612.

Accepted for publication 14th September, 1990.
Prolonged neuromuscular blockade following administration of succinylcholine occurs infrequently. The phenomenon has been seen in patients with low plasma levels of pseudocholinesterase enzyme (resulting from pregnancy, liver failure, or plasmapheresis), with atypical pseudocholinesterase, in response to large doses of succinylcholine (phase II block), and in patients exposed to plasma cholinesterase inhibitors (eye drops such as echothiophate, insecticides, chemotherapeutic agents, etc.), or combinations of these factors. ${ }^{\prime}$

We report the use of high-performance liquid chromatography (HPLC) to identify the cause of prolonged neuromuscular blockade in a child who received a total dose of $2 \mathrm{mg} \cdot \mathrm{kg}^{-1}$ succinylcholine.

\section{Case report}

A 17-mth-old, $10 \mathrm{~kg}$ white male was admitted for middle ear pressure equalizing tubes and bronchoscopy. He had a history of adenoid hypertrophy, recurrent otitis media and sleep apnoea since eight months of age. He underwent uneventful adenoidectomy at ten months of age, when halothane was used for induction of anaesthesia and succinylcholine to facilitate tracheal intubation. The apnoeic episodes became more frequent after that surgery. Preoperative physical examination and laboratory determinations revealed blood pressure 103/65 $\mathrm{mmHg}$, heart rate $118 \mathrm{~min}^{-1}$, respirations $24 \mathrm{~min}^{-1}$, haemoglobin $12.3 \mathrm{~g} \cdot \mathrm{dl}^{-1}$, haematocrit 35.5 per cent, serum $\mathrm{K}^{+} 4.5$ $\mathrm{mEq} \cdot \mathrm{L}^{-1}$ fasting blood glucose $69 \mathrm{mg} \cdot \mathrm{dl}^{-1}$. His chest $x$-ray was within normal limits. The patient received premedication with $0.2 \mathrm{mg}$ atropine IM. Monitoring during anaesthesia included non-invasive BP, pulse oximetry, ECG, precordial stethoscope, and end-tidal carbon dioxide. After a smooth mask induction of general anaesthesia utilizing oxygen and $0.5-1$ per cent halothane, a 20-gauge IV line was established through which atropine $0.1 \mathrm{mg}$ was given followed by succinylcholine $0.5 \mathrm{ml}\left(20 \mathrm{mg} \cdot \mathrm{ml}^{-1}\right)$. During bronchoscopy (ten minutes after the first dose of succinylcholine) an additional $0.5 \mathrm{ml}$ was injected from the succinylcholine syringe. Twenty 
minutes after the second injection (15 min after discontinuation of halothane), the patient remained flaccid and made no attempts at spontaneous ventilation. Evaluation of neuromuscular function using train-of-four stimulation was inconclusive (one of four). The trachea was intubated, and the patient was taken to the post-anaesthesia care unit (PAR) and the lungs were ventilated mechanically. Twenty-five minutes following arrival in the PAR ( $45 \mathrm{~min}$ after the second dose of succinylcholine) the patient initiated a brief period of shallow spontaneous respirations and jerky movements of the extremities. Ten minutes later he demonstrated strong movements and adequate respiration. The trachea was extubated and the patient recovered without further incident.

\section{Discussion}

Until the cause of apnoea could be identified, intubation and mechanical ventilation were considered appropriate management. Included in the differential diagnosis of the patient's apnoea were a history of frequent apnoeic episodes, and atypical pseudocholinesterase. However, because of a history of an uneventful previous anaesthetic which included succinylcholine, the possibility of a medication error was included as well. Several authors ${ }^{2-3}$ have reported on the incidence of intraoperative medication errors. Utting et al. reported that drug errors were responsible for 1.4 per cent of all causes of death during anaesthesia. ${ }^{2}$ Lack of standardization in drug labelling or dilution have resulted in errors in drug administration in three of ten cases ( 30 per cent). ${ }^{3}$

Since $1 \mathrm{ml}$ of solution remained in the syringe labeled succinylcholine, it was sent to the laboratory for HPLC analysis. The fluid was compared with solutions of depolarizing, and non-depolarizing neuromuscular blocking agents. The HPLC analysis was performed using a M45 solvent delivery system with a U6K injector (Water Assoc, Milford Mass, USA), a Spectroflow 773 variablelength absorbance detector (Kratos, Westwood NJ, USA), and an Omniscribe recorder (Houston Instruments, Austin Texas, USA). The mobile phase was as described by Meulemans et al. ${ }^{4}$ The detector was set at a wavelength of $210 \mathrm{~nm}$ and the flow rate was 1.5 $\mathrm{ml} \cdot \mathrm{min}^{-1}$. The results were compared with known standards.

By comparison of retention times with that of known agents, the fluid in the succinylcholine syringe was identified as a mixture of atracurium and succinylcholine (Figure). Further, determination of relative concentrations was achieved by comparing the peak heights of the unknown solution with that of peaks of known amounts of atracurium and succinylcholine. Because of the narrowness of the peak heights no attempt to integrate the areas under the peak was made. However, because the peak

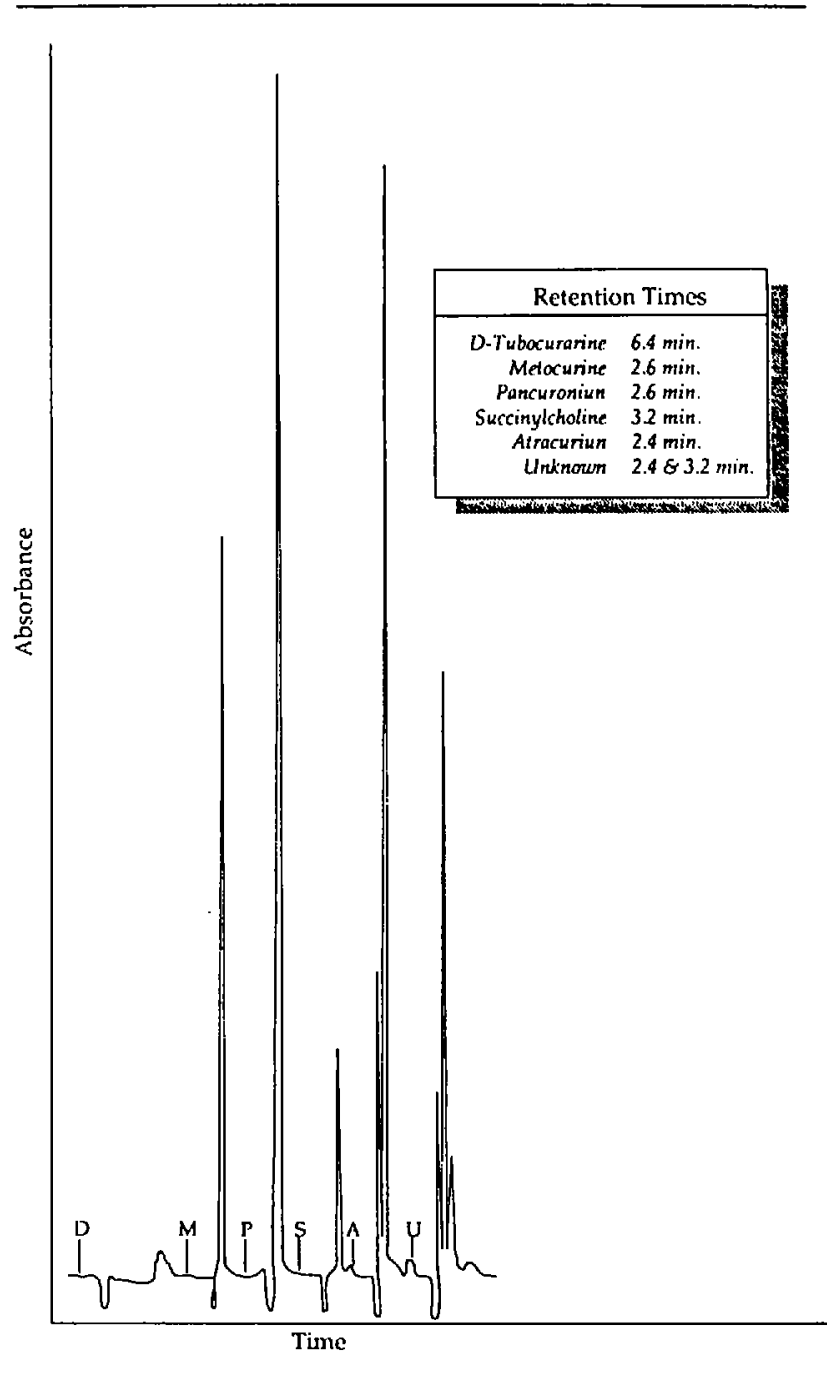

FIGURE Chromatograph of six muscle relaxants: d-tubocurarine (C), metocurine (M), pancuronium $(P)$, succinylcholine $(S)$, atracurium $(\mathrm{A})$, and unknown solution (U), showing the different absorbance and retention times. The retention times were measured in minutes from the time of injection of the solvent to the appearance of peak.

height of the unknown was approximately one-half that of the known standards, test results suggested that the concentration of the agents in the syringe was approximately half that of the standards (Figure). We believe the solution in the syringe consisted of succinylcholine ( 10 $\left.\mathrm{mg} \cdot \mathrm{ml}^{-1}\right)$ and atracurium $\left(5 \mathrm{mg} \cdot \mathrm{ml}^{-1}\right)$.

We surmise that atracurium and succinylcholine were drawn in the same syringe and erroneously labelled succinylcholine. When one milliliter of the mixture was given, the child actually received $10 \mathrm{mg}$ succinylcholine and $5 \mathrm{mg}$ atracurium. Twenty minutes following injection of the mixture (atracurium, $0.5 \mathrm{mg} \cdot \mathrm{kg}^{-1}$ ) the patient still exhibited severe neuromuscular blockade which resolved within $45 \mathrm{~min}$. The prolonged neuromuscular block was 
not an abnormal response to succinylcholine, but rather a normal response to the inadvertent administration of atracurium. By analyzing the fluid remaining in the syringe by HPLC, a definitive diagnosis was established and the patient avoided an unnecessary and potentially expensive workup. In situations where medication errors are suspected, we recommend saving syringe contents for analysis for confirmation of the agent.

\section{Acknowledgment}

We would like to thank Noreen Sullivan BS, Laboratory Technician, for the performance of HPLC.

\section{References}

1 Whitaker $M$. Plasma cholinesterase variants and the anaesthetist. Anaesthesia 1980; 35: 174-97.

2 Utting JE, Gray TG, Shelley FC. Human misadventures in anaesthesia. Can Anaesth Soc J 1979; 26: 472-8.

3 Cooper JB, Long CD, Newbower RS, Philips JH. Critical incidents associated with intraoperative exchanges of anaesthesia personnel. Anesthesiology 1982; 56: 456-61.

4 Meulemans A, MohlerJ, Henzel D, Duvaldestin PH. Quantitation of D-tubocurarine in human plasma using highperformance liquid chromatography. J Chromatogr 1981; 226: 255-8. 